\title{
Surface Segregation and Surface Defect Formation During Aluminum Billet Casting
}

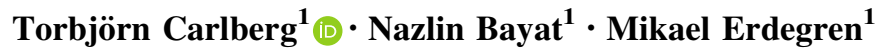

Received: 15 June 2015/Accepted: 18 August 2015/Published online: 11 September 2015

(C) The Indian Institute of Metals - IIM 2015

\begin{abstract}
In this paper the surface zone formation during direct chill casting of aluminum billets, produced by the air slip technology, is discussed. The shell zone depth and compositions have been quantitatively studied, and the surface microstructures of 6060, 6005 and 6082 alloys are compared and coupled to surface appearances. The understanding of the results is based on the exudation of liquid metal through the mushy zone and the fact that the exudate liquid is contained within a surface oxide skin, and the oxide skin movements are coupled to various surface appearances. The major defects that occur during billet castings are different kinds of vertical drags or horizontal bandings, also called lapping. The structures coupled to these defects and theories for their formation are discussed.
\end{abstract}

Keywords Aluminum alloys - Direct chill (DC) casting Surface segregation · Surface defects

\section{Introduction}

The direct chill (DC) casting technique to produce semifinished aluminum castings, i.e. billets for extrusion and ingots for rolling, has been developed since the 1930s [1]. The principle, which is still valid, is a two-stage cooling: (i) primary cooling at a mold surface, (ii) water spraying directly on the surface [2-4]. Improvements on this technique have mainly focused on changes to the primary cooling, where a water-cooled metal mold has been

Torbjörn Carlberg

torbjorn.carlberg@miun.se

1 Department of Natural Science, Mid Sweden University, Holmgatan 10, 85170 Sundsvall, Sweden replaced by different techniques to minimize cooling. The drive for development comes from the profile extrusion industry, which can increase the productivity and quality of extruded profiles by improving the billet and structure. Hot top casting supported by airflow against the casting surface during the primary cooling is currently the standard procedure in order to achieve acceptable billet surfaces. Surface segregation in DC cast billets has been discussed in the literature [4-11]. The formation of the so-called lapping surface or Bergmann zones [4] with a wavy or banded surface appearance in these researches has been the subject of different theories. The goal is to minimize the depth of the macro-segregation zone, which is the governing factor for the existence of different unwanted phases in the surface region.

Defects appearing on the outer surfaces can be coupled to the structure of the surface zone and this paper aims to obtain an over-all picture of the surface formation during air-slip DC casting of aluminum. The importance of the oxide skin in the meniscus region and the change in coherency temperature between the different 6xxx alloys, discussed here, is derived from the literature [12-16]. In this paper an extended discussion, to cover all observed phenomena, will be done, and only the casting technique using hot top air-slip will be considered.

\section{Results}

The compositions of the alloys used in the present study are given in Table 1, and concentration profiles measured at a smooth surface and at a vertical drag (VD) defect are shown in Fig. 1a, b, respectively.

In Fig. 2 a SEM image directly from an unprepared surface of a billet is shown. Such observations have been 
Table 1 Chemical compositions of alloys

\begin{tabular}{llllllll}
\hline Alloy & $\mathrm{Si}$ & $\mathrm{Fe}$ & $\mathrm{Cu}$ & $\mathrm{Mn}$ & $\mathrm{Mg}$ & $\mathrm{Cr}$ & $\mathrm{Ti}$ \\
\hline 6060 & 0.425 & 0.2 & 0.024 & 0.02 & 0.475 & 0.024 & 0.024 \\
6005 & 0.65 & 0.22 & 0.056 & 0.15 & 0.54 & 0.001 \\
6082 & 0.96 & 0.19 & 0.001 & 0.46 & 0.63 & 0.0006 & 0.011 \\
\hline
\end{tabular}

(a)

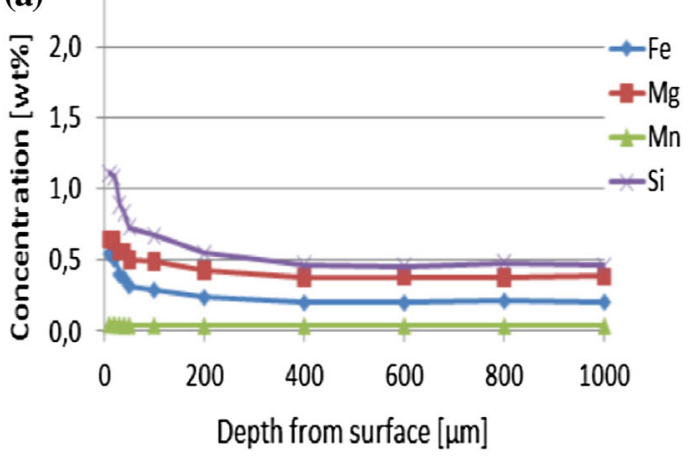

(b)

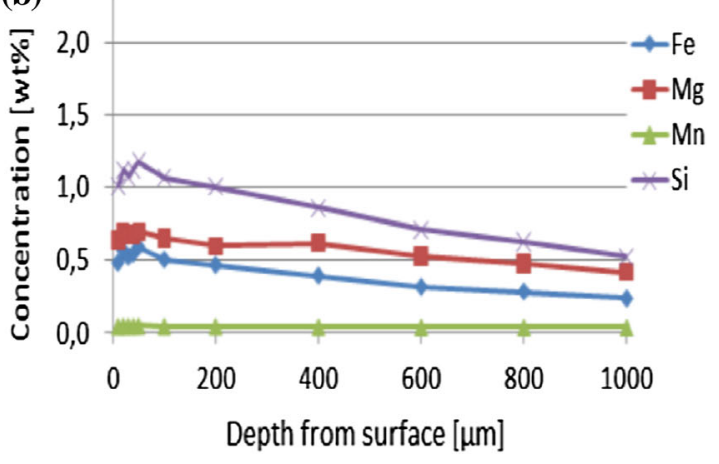

Fig. 1 Concentration profiles at the surface of a a defect free surface in a 6060 alloy and b at a VD in a 6060 alloy, from [12]

reported earlier $[7,8]$, but not explained. $\beta-\left(\mathrm{Al}_{5} \mathrm{FeSi}\right)$ platelets is the dominating phase, but to the right not only some $\alpha-\mathrm{Al}_{15}(\mathrm{Fe}, \mathrm{Mn})_{3} \mathrm{Si}_{2}$ particles in a dendritic shape can be seen, but also $\mathrm{Mg}_{2} \mathrm{Si}$ can occur [16].

Surface appearances showing a smooth surface and defects of horizontal nature are shown in Fig. 3, and in Fig. 4 structures coupled to smooth surface and banded surface are shown.

Figure 5 shows vertical defects of different kinds. Figure $5 \mathrm{a}$ and $\mathrm{b}$ are vertical drag (VD) defects normally extended along most of the billet length increasing in severity towards the end of casting. Figure $5 \mathrm{c}$ shows intermittent shallow defects normally occurring only on 6082 but sometimes visible also on other alloys. Another type of vertical defect occurring in all the alloys is shown

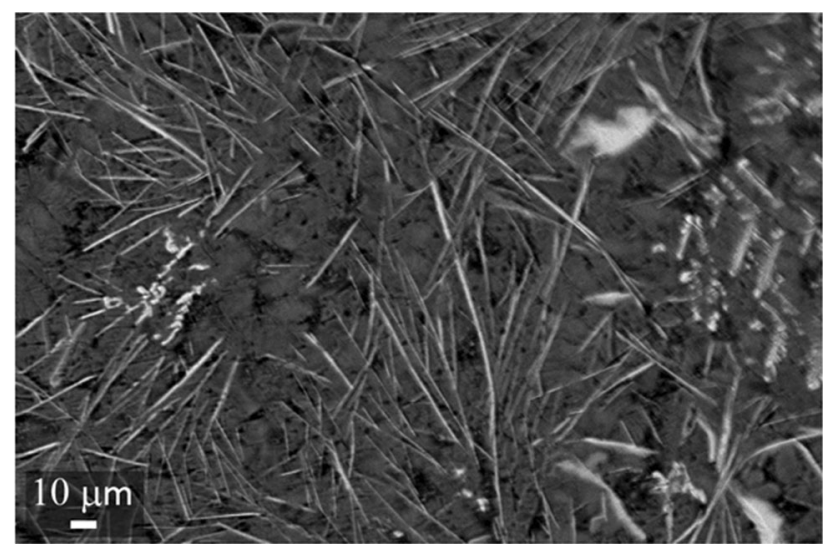

Fig. 2 SEM image of billet surface, showing $\beta$-phase plates and some $\alpha$-phase dendrites to the right, from [16] in Fig. 6, which consist of aligned spots, which sometimes are called "snail trails".

Figure 7 shows the structure behind VD defects, and it can be seen that the segregation to the defects can be very different. It is observed [14] that in 6005 alloys, which often is regarded as the most sensitive to the occurrence of VD defects, with a wide outer appearance, normally a more shallow segregation zone under the defect can be observed, as can be seen in Fig. 7b. In 6060 alloys, rather tiny VD lines can have deep segregation associated with them, as can be seen in Fig. 7a.

\section{Discussion}

\subsection{Surface Zone Formation}

The segregation to the surface zone in billets are often talked about as an inverse segregation. However, this hypothesis is originally used for cases when the segregation occurs in an opposite direction to the direction of solidification. This is caused by volumetric shrinkage, that has been discussed frequently in the literature, [17-20]. At the surface of billets the concentration increases towards the surface, but is not a result of shrinkage. Instead, the solidification in the outer layer proceeds outwards. This fact was pointed out already by McGubbin [7], but not always acknowledged in discussions of the surface zone. In [15] both the surface segregation and transition to cellular growth are quantitatively treated. Classical Scheil segregation and constitutional super-cooling criteria models can 

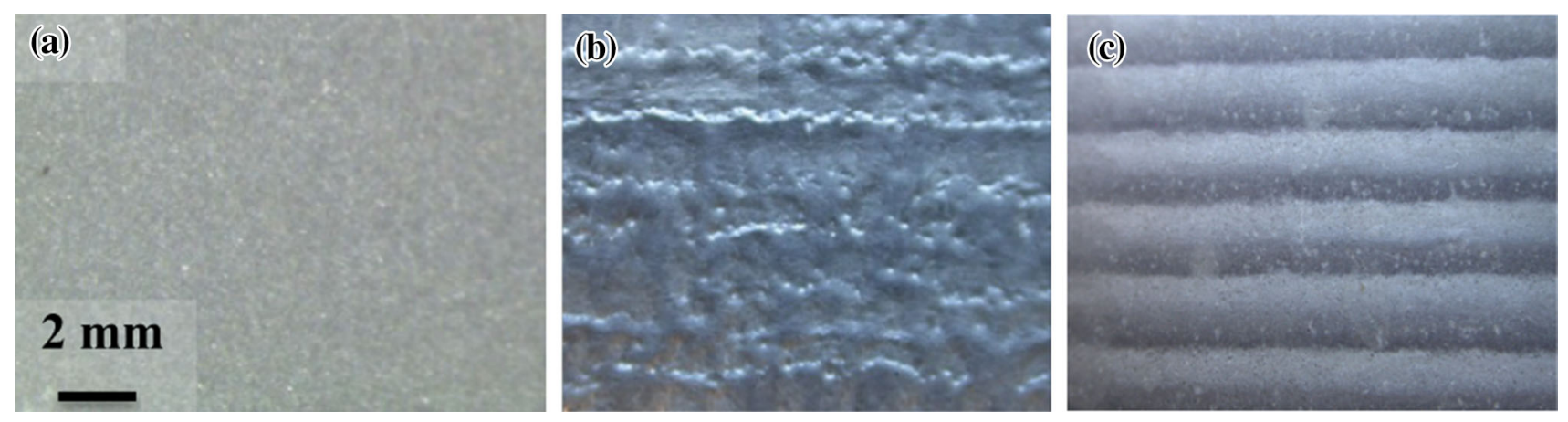

Fig. 3 Macro surface pictures showing a a smooth defect free surface on 6082 alloy, $\mathbf{b}$ a banded irregular surface on a 6082 alloy and $\mathbf{c}$ a banded regular surface on a 6005 alloy

Fig. 4 Microstructures at a a smooth surface and $\mathbf{b}$ a banded structure with meniscus marks, where the start of a meniscus mark is shown with an arrow for 6060 alloy. From [15]

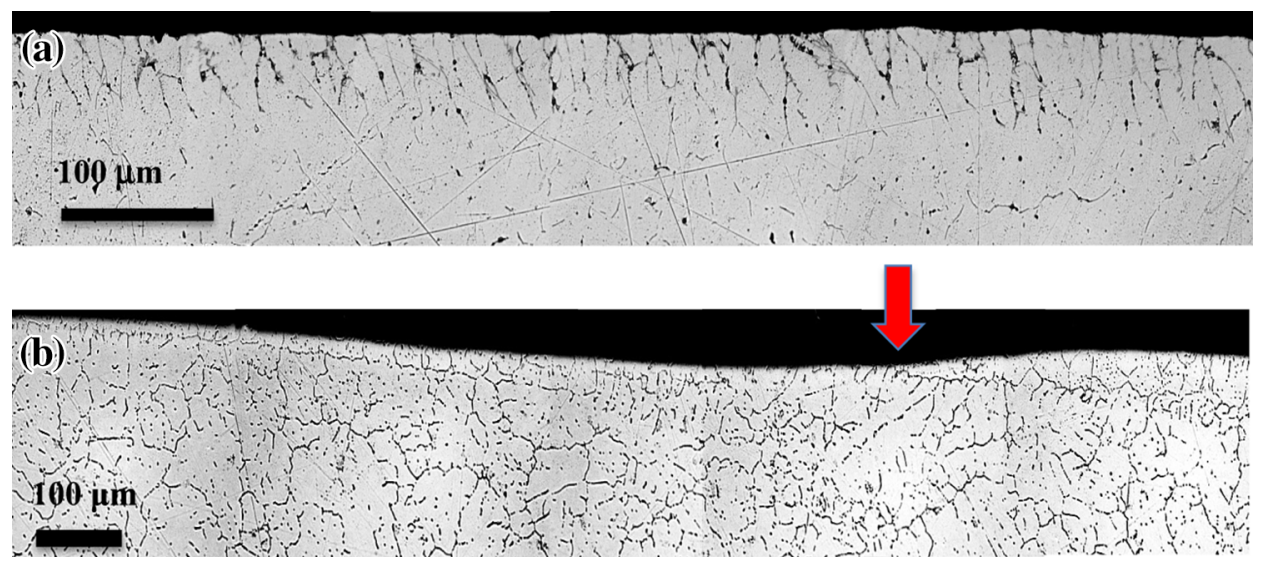

successfully model both the segregation profiles and the start of cellular growth. When the solidification ends at the very surface, i.e. at the oxide skin, the alloy element concentration is very high and a lot of secondary phases form. In Fig. 2 such phases are shown laying directly on the surface of the billet, and they have the shape of primary precipitates growing into a liquid, indicating a high alloy content. When the phases have been formed as nearly a two-dimensional thin layer, the remaining liquid probably is sucked down between the cell boundaries due to continuing solidification shrinkage, and thus the phases apparently lay on the surface.

A necessary condition for the outer layer to solidify outwards is that a layer of exudated melt is pressed out between the semisolid shell and the oxide skin below the meniscus. This mainly depends on the pressure from the metal head, and can be decreased by lowering that head, as has been reported recently in [11]. There is also another necessary condition for the outer layer to solidify outward which is to have a thermal gradient with cooling from inside. This is achieved by the double action of the upstream conduction [20] from the direct water cooling about $15 \mathrm{~mm}$ below the graphite ring, and the low heat transfer from the surface due to the air film between the graphite ring and surface.
Fig. 6 Line of spot defects aligned in the vertical direction along the billet, from [14] 

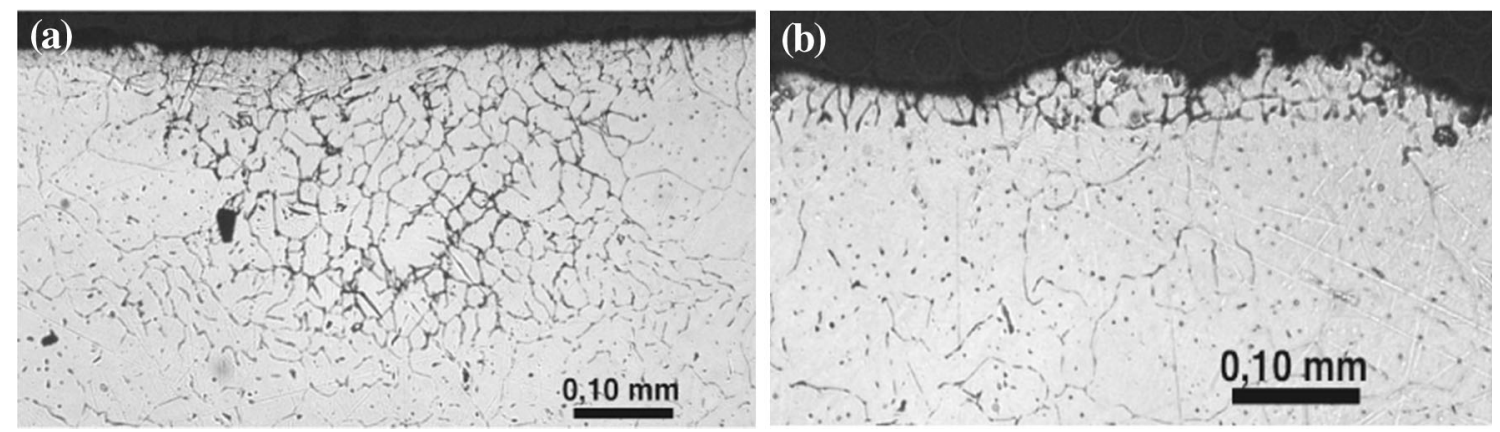

Fig. 7 The structure at two vertical drag defects shown in transverse cuts. a is from a 6060 alloy and b from a 6005 alloy, from [14]

\subsection{Horizontal Banding}

The described surface formation is always present, even when the surface is perfectly smooth, as in Fig. $4 a$, but if the metal head pressure starts to fluctuate, the exudated layer thickness also fluctuates, and so the severity of the surface segregation, as can be seen in Fig. 4b. At such conditions, the so called meniscus marks can also develop as shown in Fig. 4b. They form when the oxide skin on the meniscus pushes together floating crystals in the semi-solid region towards the coherent lower region. When the pressure subsequently increases, melt is pressed against the oxide skin, which move out towards the graphite ring and new melt fill the volume between the meniscus mark and oxide. The depth of the segregation zone is clearly larger compared to a smooth surface when fluctuations start, and surface appearances as shown in Fig. 3b, c, indicate clearly thicker segregation zones than what can be expected from surfaces like in Fig. 3a. Also the phases occurring on the surface, Fig. 2, has a cyclic appearance on a banded surface [15], which can be coupled to the thicknesses of the segregation zone and the segregation coefficient for $\mathrm{Fe}$ and $\mathrm{Si}$, respectively. At thicker zones the Fe:Si ratio increases at the end of solidification due to stronger segregation of $\mathrm{Fe}$ and then the $\alpha$-phase dominates. For similar reason, at lower Fe:Si ratio, $\beta$-phase will dominate on the 6005 surfaces due to higher $\mathrm{Si}$ content in the base alloy.

The difference between Figs. 3b, c, i.e. 6082 and 6005, can be coupled to the importance of the different coherency temperatures for the two alloys. If coherency occurs at a lower temperature, as for the 6082 alloy, no meniscus marks form as only point contacts occur between the fluctuating oxide skin and the coherent material, and melt is pressed out between the contact points irregularly, and a surface as shown in Fig. 3b forms.

\subsection{Vertical Defects}

The vertical defects shown in Figs. 5 and 6 are results of different surface disturbances. The line of spots shown in
Fig. 6 are caused by disturbances at the top plate [14], where the oxide skin or flowing metal can be connected to flaws on the surface, however, it was reported [15] that the concentration of $\mathrm{F}$ and $\mathrm{Na}$ strongly increased in the spot centers, indicating the influence of bath (cryolite $\left.\mathrm{Na}_{3} \mathrm{AlF}_{6}\right)$ rests in the formation of the spots. The segregation associated with this type of defects is however negligible.

The more severe VD defects in Figs. 5a, b are associated with disturbances at the graphite ring. Important here is upto what level along the ring the contact occurs in the relation to the coherency temperature. If the contact occurs below the coherency temperature, tension and thus strain can influence the semi-solid structure, which may be deformed and sucked in liquid with high alloy content, the result shown for an 6060 alloy in Fig. 7a. If the coherency temperature is lower, as for 6005 , no force is transferred from the contact to the semi-solid, and only the two-phase liquid close to the surface is influenced, and the result is shown in Fig. 7b. Here a paradox is that, though the latter VD defect looks much larger from outside of the billet but it has a more shallow segregation. For even higher alloy contents, as for 6082, and thus lower coherency temperatures, contacts with the graphite ring causes smaller disturbances of the surface, such as the intermittent lines shown in Fig. 5c, with the implication of less segregation.

\section{Conclusions}

The surface appearances as well as vertical drag formation are both strongly coupled to the coherency point for different alloys, and therefore relatively small variations in composition of the 6xxx series alloys have large impact on the surface quality.

The oxide skin and it's movements at the meniscus are important for the surface formation and necessary for the DC casting to give a high quality surface. 


\section{References}

1. Schneider W, Light Metals, TMS, Warrendale (2002) p 433.

2. Eskin D G, Savran V I, and Katgerman L, Metall Mater Trans A 36A (2005) 1965.

3. Evans J W, and Jones W K, Light Metals, TMS, Warrendale (2002) p 669.

4. Bergmann W J, Metall Trans 1(1970) p 3361.

5. Iverson F, PhD Thesis, NTNU, Trondheim (2002).

6. Mortensen D, Henriksen B R, Hamdi M, and Fjaer H G, Light Metals, TMS, Warrendale (2008) p 773.

7. McGubbin J G, Light Metals, TMS, Warrendale (1975) p 756.

8. Benum S, Håkonsen A, Hafsås J E, and Sivertsen J, Light Metals, TMS, Warrendale (1999) p 737.

9. Bainbridge I F, Taylor J A, and Dahle A K, Light Metals, TMS, Warrendale (2004) p 693.

10. Ekenes J M, Light Metals, TMS, Warrendale (1991) p 933.
11. Håkonsen A, Hafsås J, and Ledal R, Light Metal, TMS, Warrendale (2014) p 873.

12. Erdegren M, and Carlberg T, Light Metals, TMS, Warrendale (2011) p 675.

13. Erdegren M, Ullah M, and Carlberg T, IOP Conf Ser 27 (2012) 012013.

14. Carlberg T, and Jarfors A E W, Metall Mater Trans B 45B (2014) 175.

15. Bayat N, and Carlberg T, JOM 66 (2014) 700.

16. Bayat N, and Carlberg T, IOP Conf Ser (2015) (in press).

17. Flemings M C, Solidification Processing, Mc Graw-Hill, New York, NY, 1974.

18. Flemings M C, Iron Steel Inst Jpn Int 40 (2000) 833.

19. Minakawa S, Samarasekera I V, and Weinberg F, Metall Trans B 16B (1985) 595.

20. Bainbridge I F, Grandfield J F, Taylor J, Proceedings of the Aluminium Cast House Technology 2005, (2005), p 85. 